\title{
Overexpression of Galactinol Synthase 1 From Solanum Commersonii (ScGo/S1) Confers Freezing Tolerance In Transgenic Potato
}

\section{Feiyan He}

Chinese Academy of Agricultural Sciences

Jianfei Xu

Chinese Academy of Agricultural Sciences

\section{Yinqiao Jian}

Chinese Academy of Agricultural Sciences

\section{Shaoguang Duan}

Chinese Academy of Agricultural Sciences

\section{Jun $\mathrm{Hu}$}

Chinese Academy of Agricultural Sciences

\section{Liping Jin}

Chinese Academy of Agricultural Sciences

Guangcun Li ( $\square$ liguangcun@caas.cn )

Chinese Academy of Agricultural Sciences

\section{Research Article}

Keywords: S. commersonii, ScGolS1, freezing tolerance, RFOs, ERF transcription factor

Posted Date: November 1st, 2021

DOl: https://doi.org/10.21203/rs.3.rs-985498/v1

License: (9) (i) This work is licensed under a Creative Commons Attribution 4.0 International License. Read Full License 


\section{Abstract}

Potato (Solanum tuberosum L.) is the fourth largest food crop in the world. Low temperature causes serious damage to potato plants every year, and freezing tolerance has become a hot spot in potato research. Galactinol synthase (GolS) is a key enzyme in the synthesis of raffinose family oligosaccharides (RFOs), and plays an important role in the response of plants to abiotic stress. In this study, the ScGolS1 gene from $S$. commersonii was cloned and introduced into the $S$. tuberosum cultivars 'Atlantic' and 'Desiree' via Agrobacterium-mediated transformation. Phenotyping assay showed that overexpression of the ScGolS1 could significantly improve freezing tolerance in transgenic potato plants. Further physiological and biochemical results showed that the relative conductivity, malondialdehyde (MDA) content, and 3,3'-Diaminobenzidine (DAB) staining of the transgenic lines decreased, and the plant survival rate increased compared with wild type (WT). Moreover, $C B F 1, C B F 2, C B F 3, C B F$ downstream cold responsive genes COR413, COR47 and ERF transcription factor genes ERF3, ERF4, ERF6 in the ethylene signaling pathway were all induced by freezing treatment, while higher levels were observed in ScGolS1 overexpression lines compared with WT. In addition, other genes such as MIPS, STS and RS genes from RFO metabolic pathway and some sugars content were altered in response to freezing treatment. This indicates that overexpression of the ScGolS1 gene induced both the regulation of the ethylene signaling pathway and the metabolism of raffinose series oligosaccharides, regulating the balance of sugar composition and improved anti-peroxidation capacity, and thereby improved freezing tolerance in potato. These results provide theoretical support and genetic resources for freezing tolerance breeding in potato.

\section{Key Message}

\section{ScGolS1 overexpression altered sugar composition and enhanced freezing tolerance in transgenic potato via inducing ET signaling and CBF pathways.}

\section{Introduction}

The growth and development of plants can be affected by various adverse environmental conditions such as biotic and abiotic stresses (Zhu 2016). The biosynthesis of soluble carbohydrates in plants is of great significance to plant growth, development, and environmental adaptability, especially when plants face adverse conditions such as low temperature, drought, and high salt levels. The cellular biosynthesis and content of soluble sugars such as glucose, sucrose, and raffinose family oligosaccharides (RFOs) are increased, which enhances the osmotic adjustment ability of plant cells, thereby improving the tolerance of plants to abiotic stress (Sun et al. 2013; Salvi et al. 2018). Soluble carbohydrates can enhance osmotic pressure and energy metabolism in cells and act as signal molecules to improve freezing tolerance in plants (Theocharis et al. 2012). Generally, sucrose accumulation plays an important role in stabilizing the cellular membrane and maintaining turgor under low temperature stress (Guy et al. 1992; Strand et al. 2003). The concentration of RFOs is second only to sucrose, and mainly includes three types: raffinose, stachyose, and verbascose. Galactinol synthase (GolS, EC 2.4.1.123) catalyzes the reaction of UDP- 
galactose and inositol to produce galactosyl inositol, which provides galactosyl groups that undergo transfer catalysis to synthesize RFOs. This is one of the most important steps in the RFOs metabolic pathway. GolS, the key regulatory enzyme in this step, was first discovered in pea seeds. It regulates the accumulation of RFOs in plants, and plays an important role in plant growth and environmental adaptability (Bachmann et al. 1994; Sengupta et al. 2012; Sonali et al. 2015).

The GolS gene family is classified as a subfamily of the glycosyltransferase (GTs) GT8 gene family. In addition to the classic structural motifs DxD and HxxGxxKPW of GT8 family proteins, several other unique conserved motifs are present in GolS proteins: YNL, FAEQDFLNMF, YFNAGMFVFEP, and KLRIWEFVEY (Yin et al. 2010). GolS is a key enzyme in the synthesis of RFOs, and it participates in the abiotic stress response in plants (Sengupta et al. 2012). The Arabidopsis AtGolS gene family has seven members, of which three (AtGolS1-3) are responsive to stress. AtGolS1 and AtGolS2 expression is upregulated by drought and salinity, but not in response to low temperature stress, while expression of AtGolS3 is induced by low temperature stress but not by drought and high salinity (Panikulangara et al. 2004). MdGolS2 is the main GolS gene expressed during dormancy in apple, and it helps to protect the dormant buds from the effects of lack of water (Falavigna et al. 2018). In winter wheat, overexpression of TaGolS1 and TaGolS2 can significantly improve the resistance to low temperature (Shimosaka et al. 2015). In chickpeas, although the overexpression of CaGolS1 and CaGolS2 is beneficial to improve seed vigor and longevity, the two genes respond to different stresses (Prafull et al. 2018; Salvi et al. 2018). Overexpression of Ammopiptanthus nanus AnGolS1 in tomato causes the plants to accumulate galactosyl inositol, which acts as a sugar signal in the ethylene signaling pathway and plays an important role in adaptation to low temperature stress (Liu et al. 2019).

The ethylene (ET) signaling pathway is known to be involved in the response to low temperature stress (Eremina et al. 2016). Ethylene-responsive factors (ERFs), which are downstream regulatory factors of the ET signaling pathway, modulate the expression of downstream stress-response genes. ERF proteins play a key role in directing changes in gene expression in response to different forms of environmental stress (Nakano et al. 2006). Overexpression of the EREBP/ AP2 DNA-binding protein DREB1A not only induces strong expression of the target genes under unstressed conditions, but also enhances the drought and freezing tolerance of transgenic Arabidopsis plants (Liu et al. 1998). Ectopic expression of a pepper ERF/AP2-type transcription factor, CaPF1, also improves the freezing tolerance of Arabidopsis (Yi et al. 2004). In addition, ERF proteins also positively promote ET biosynthesis via feedback regulation; for instance, overexpression of tomato TERF2/LeERF2 can enhance the ET production and freezing tolerance of tobacco and tomato plants (Zhang and Huang 2010).

Potato (Solanum tuberosum L.) is the fourth largest food crop in the world. Low temperature can cause serious damage to potato plants, resulting in reduced or even no harvest (Chen et al. 1999). Freezing tolerance has become a major focus in potato research. The commonly-grown potato cultivars have poor freezing tolerance and no obvious cold acclimation ability (Chen et al. 1980). It is difficult to breed varieties with freezing tolerance by intraspecific hybridization of common cultivars, although there are abundant freezing-tolerant resources in wild potato species such as $S$. commersonii, S. malmeanum, and 
S. acaule (Vega et al. 1995). A previous study reported that the semi-lethal temperature $\left(L T_{50}\right)$ for $S$. commersonii before cold acclimation is $-4.5^{\circ} \mathrm{C}$, and the $\mathrm{LT}_{50}$ after cold acclimation can reach $-11.5^{\circ} \mathrm{C}$. $S$. commersonii is one of the most freezing-tolerant of the wild potato species (Aversano et al. 2015). Because the endosperm balance number (EBN) in $S$. commersonii is 1 , the difference in EBN makes it sexually incompatible with tetraploid potato cultivars (EBN is 4 in $S$. tuberosum). Cloning the freezing tolerance genes from $S$. commersonii and introducing them into cultivated varieties is an effective method to prevent and control the harmful effects of low temperature and frost. Although GolSgenes have been identified and isolated in many plants such as Arabidopsis thaliana (Falavigna et al. 2018), tomato (Liu et al. 2019), corn (Gu et al. 2013), tea tree (Zhou et al. 2017), and salvia (Wang et al. 2012), there are few studies of GolS genes in potato. The goal of our study is to clone ScGolS1 gene from the wild diploid freezing-tolerant potato species $S$. commersonii, verify the function of the gene through genetic transformation, and then to explore the important role of ScGolS1 in the freezing tolerance pathway in plants. Our results will increase our understanding of freezing tolerance in plants and provide genetic resources for breeding of freezing tolerance in potato.

\section{Materials And Methods}

\section{Plant materials and growth conditions}

The tetraploid S. tuberosum potato cultivars 'Atlantic' (B44) and 'Desiree' (B7) are freezing-sensitive, and the diploid wild potato species $S$. commersonii (W3) is freezing-tolerant. All materials were preserved in the form of tissue culture seedlings or seed potatoes in the potato laboratory of the Institute of Vegetables and Flowers, Chinese Academy of Agricultural Sciences. Tissue culture conditions for potato propagation: $30 \mathrm{~mL}$ Murashige-Skoog (MS) solid medium ( $\mathrm{pH}=5.8-6.0$ ) containing $3 \%$ sucrose, $2500 \mathrm{Lx}$ light intensity, $22 \pm 1{ }^{\circ} \mathrm{C}$ for $16 \mathrm{~h}$ in light and $8 \mathrm{~h}$ in dark, $80 \%$ humidity. Transplanting tissue culture seedlings: tissue cultured seedlings at 3-4 weeks of age were transplanted into $10 \times 10 \mathrm{~cm}$ plastic flower pots containing seedling substrate and grown in a solar greenhouse ( $14 \mathrm{~h}$ light/ $10 \mathrm{~h}$ dark) for 30 days. All samples collected were immediately frozen in liquid nitrogen and then kept in a refrigerator at $-80^{\circ} \mathrm{C}$ before use.

\section{ScGolS1 gene cloning and bioinformatics analysis}

Total RNA was extracted from seedlings of the wild potato species $S$. commersonii using the Plant Polysaccharide Polyphenol RNA Extraction Kit (GeneBetter, China). First-strand cDNA was synthesized with the Script III RT Kit With gDNA Eraser (GeneBetter, China), and then the primer pair ScGolS-CDS-F/R with added restriction sites was used to amplify the ScGolSCDS (Supplemental Table S1). The pBI121 plasmid was digested with $\mathrm{Xba}$ I and $\mathrm{Xma} \mathrm{I}$ (NEB, USA) overnight at $37^{\circ} \mathrm{C}$, examined by $0.8 \%$ agarose gel electrophoresis, and the linearized vector was purified from the gel. The GolSCDS was cloned using the Seamless Cloning Reaction System (Vazyme, China), and individual positive clones were selected and sequenced (BGI, China). 
The databases used in this study were the Potato Genome Sequencing Consortium (PGSC) database (http://solanaceae.plantbiology.msu.edu/) and the National Center for Biotechnology Information database (https://www.ncbi.nlm.nih.gov/). DNAman software was used to perform sequence alignments; MEGA5.0 software was used to construct a phylogenetic tree by NJ (neighbor-joining) method; ProtParam (https://web.expasy.org/protparam/) was used to predict the basic physical and chemical properties of proteins; TMHMM (https://www.cbs. dtu.dk/services) was used for transmembrane domain prediction; Protscale (https://web.expasy.org/protscale/) was used for protein hydrophobicity analysis; PSORT Prediction (https://psort.hgc.jp/form.html) was used to predict the subcellular localization of proteins; Smart (http:/smart.embl-heidelberg.de/) was used to predict the conserved domains in amino acid sequences; SOPMA (https://npsa-prabi.ibcp.fr) was used to predict the secondary structure of proteins.

\section{ScGolS1 gene transformation and plant phenotype identification}

The recombinant vector plasmid CaMV35S-pBI121-ScGolS1 was transformed into Agrobacterium tumefaciens GV3101, and the bacteria liquid was used to infect potato stems. Callus buds were induced on callus induction medium and bud induction medium, and the callus buds were further induced to root and form shoots. A combination of the vector primer pair 73F/211R and gene-specific primers was used in PCR amplification to identify positive seedlings (Supplemental Table S1), the initial identification was performed on tissue culture seedlings and the second identification was performed on the potted seedlings after transplanting.

One month old seedlings were transferred to a low-temperature incubator or outdoor with three replicates for freezing identification, and the temperature and humidity were monitored in real time. Lowtemperature incubator appraisal: plants were subjected to freezing treatment at $-2 \pm 0.5^{\circ} \mathrm{C}$ for $24 \mathrm{~h}$, and then allowed to recover at $23^{\circ} \mathrm{C}$ during the day $/ 20^{\circ} \mathrm{C}$ at night for $1-2$ days, during which the temperature would rise/fall slowly.

\section{T-DNA insertion sites analysis}

Three nested specific primers SP1, SP2, and SP3 were designed based on the known sequence of the recombinant vector CaMV35S-pBI121-ScGolS1. These nested specific primers were combined with four sets of degenerate primers, LAD1, LAD2, LAD3, and LAD4 (Supplemental Table S1), and used in hiTAILPCR for three consecutive rounds of amplification using the method of Liu and Chen with slight modifications (Liu et al. 2007). The sequences were used as queries to search the PGSC database to identify the T-DNA insertion sites, and the T-DNA insertion site sequences were then analyzed.

\section{Real-time quantitative PCR analysis}

30 days old seedlings were subjected to different freezing stress: $(1) 20^{\circ} \mathrm{C}, 12^{\circ} \mathrm{C}, 4^{\circ} \mathrm{C}, 2^{\circ} \mathrm{C}$ and $0{ }^{\circ} \mathrm{C}$ for $24 \mathrm{~h}$; (2) $-1^{\circ} \mathrm{C}$ for $0,12,24$ and $48 \mathrm{~h}$. The total RNA from root, stem, leaf of transgenic lines and WT plant was extracted by the Plant Polysaccharide Polyphenol RNA Extraction Kit (GeneBetter, China) according to the manufacturer's instructions, and cDNA was synthesized via the Script III RT Kit with gDNA Eraser 
(GeneBetter, China) as directed by the manufacturer. The EF-1 $a$ gene was used as the internal control for normalization of gene expression in real-time quantitative PCR (qRT-PCR) (Supplemental Table S1). qRTPCR were performed with SYBR Green Master Mix (Mei5bio, China) on a Roche LightCycler PCR instrument (Roche, USA), using the following amplification procedure: a $95^{\circ} \mathrm{C}$ pre-denaturation for $5 \mathrm{~min}$, followed by 40 cycles of denaturation at $95^{\circ} \mathrm{C}$ for $15 \mathrm{~s}$, annealing at $58^{\circ} \mathrm{C}$ for $15 \mathrm{~s}$, and extension at $72^{\circ} \mathrm{C}$ for $45 \mathrm{~s}$. The $2^{-\triangle \Delta C t}$ method was used to analyze the expression data (Livak et al. 2001).

\section{Physiological and biochemical determination}

Transgenic and WT plants grown in a low-temperature incubator were treated with $-1^{\circ} \mathrm{C}$ for $24 \mathrm{~h}$, and plants grown under normal conditions for $24 \mathrm{~h}$ were used as control. The relative conductivity was determined according to the method of Cao et al. (Cao et al. 2007), with a slight modification. MDA content was determined using a malondialdehyde detection kit (Solarbio, China) (Wang et al. 2019). DAB staining was performed according to the method of Jambunathan with minor modifications (Jambunathan et al. 2010).

\section{Sugar content detection and analysis}

Soluble sugars were extracted from leaves under freezing treatment. The mixed sample was ground in liquid nitrogen, and then $1 \mathrm{~g}$ of ground powder was distributed in $100 \mu \mathrm{L}$ water, then $1 \mathrm{~mL}$ saccharide internal standard $(0.4 \mathrm{mg} / \mathrm{mL}$ arabinose water) was added to the water-soluble potato leaves extracts. After sonication and centrifugation, the samples were filtered through a $0.22 \mu \mathrm{m}$ polyethersulfone ultrafiltration membrane and mixed with an equal volume of acetonitrile for analysis. Saccharide was measured by UPLC-MS/MS (ACQUITY UPLC I-Class-Xevo TQ-S Micro, Waters). For saccharide analysis, an ACQUITY UPLC BEH Amide $1.7 \mu \mathrm{m}$ column was used as the analytical column $(2.1 \times 100 \mathrm{~mm}$; Waters). The mobile phase was composed of acetonitrile as solvent $A$ and $1 \mathrm{mg} / \mathrm{mL}$ ammonium hydroxide as solvent $\mathrm{B}$. The temperatures of the column and autosampler were $60^{\circ} \mathrm{C}$ and $4^{\circ} \mathrm{C}$, respectively. Each saccharide was separated by increasing the solvent B concentration from $10-20 \%$ over 6 min after the first 2 min of the run at $10 \%$ using a flow rate of $0.2 \mathrm{~mL} / \mathrm{min}$, followed by washing with $10 \%$ solvent B for 2 min. Data analysis was performed using MassLynx V4.1 (Waters). Sugar concentrations were calculated based on the standard curve for each sugar and calibrated with the recovery of the whole analysis procedure.

\section{Statistical Analysis}

Three biological replicates were analyzed for each treatment. Data values presented as the means \pm SD. Significant differences were determined using Student's t-test with $p<0.05$ and $p<0.01$ considered to be statistically significant and highly significant, respectively.

\section{Results}


A previous study reported that the $\mathrm{LT}_{50}$ of $S$. commersonii before cold acclimation was $-4.5^{\circ} \mathrm{C}$, and after cold acclimation reached $-11.5^{\circ} \mathrm{C}$. In order to verify the freezing tolerance of $\mathrm{W} 3, \mathrm{~W} 3$ plants were exposed to $-5^{\circ} \mathrm{C}$ for $24 \mathrm{~h}$, only a few leaves and stems showed wilting after recovery, proving that W3 had strong freezing torlerance (Fig. S1a). The field natural frost test (minimum temperature $-5^{\circ} \mathrm{C}$ ) also showed that the freezing tolerance of W3 was stronger than other wild potato materials such as $S$. acaule, $S$. demissum, S. albicans and so on (Fig. S1b-c). RNA-seq analysis of W3 in the early stage showed that the ScGolS1 gene was up-regulated in response to freezing stress. In this study, the full-length CDNA of ScGolS1 was cloned from W3 based on the EST sequence of the gene (Fig. S3a). ScGolS1 is located on potato chromosome 1, the open reading frame is $969 \mathrm{bp}$ in length. The ScGolS1 gene encodes a protein of 322 amino acids with a molecular weight of $36.8 \mathrm{kD}$ and an isoelectric point of 6.61 ; the instability coefficient is 41.79 , which indicates an unstable protein; the average hydrophilicity coefficient is -0.272 , which shows that ScGolS1 is a hydrophilic intramembrane protein. Online software predicts that ScGolS1 is located in the cytoplasm, and the main secondary structural features of the protein are alpha helix and random coil.

Using Protein BLAST global alignment, we found that the amino acid sequence identity between ScGolS1 (ADW78839.1) and ScGolS2 (ADW78841.1) and ScGolS3 (ADW78843.1) was 57.74\% and 61.13\%, respectively, while the similarity between ScGolS2 and ScGolS3 was $77.26 \%$. The amino acid similarity between ScGolS1 and StGolS1 (ADW78846.1) from S. tuberosum was $96.89 \%$, and the amino acid consistency between SpGolS1 (XP_015071077.1) from S. pennellii and SIGolS1 (NP_001234486.2) from S. lycopersicum was $>90 \%$. Multi-sequence alignment showed that the GolS protein contained conserved domains, such as a substrate binding domain, a manganese ion $\left(\mathrm{Mn}^{2+}\right)$ binding site (DGD), and a carboxy (C) terminal typical hydrophobic pentapeptide (A(S)PSAA), indicating that these GolS proteins had the ability to catalyze the synthesis of inositol and UDP-galactose into galactinol (Fig. 1a). However, there were large sequence differences in the conserved domains of the GolS proteins. In addition, there were many serine (S) phosphorylation sites in the GolS1 sequence., our hypothesis was that the function of GolS protein was achieved through phosphorylation.

Phylogenetic analysis showed that the GolS proteins from different Solanaceae species were grouped into three major clades (Fig. 1b), among which ScGolS1, StGolS1, and SIGoIS1 were in clade III, ScGolS2, SpGolS1, StGolS2, and NtGolS1 were in clade II, and ScGolS3, StGolS3, SpGolS2, SIGolS2 and NtGolS2 were in clade I. A previous study showed that the activity of SIGolS2 in cultivated tomato was higher than that of SIGolS1 (Liu et al. 2019). The results of phylogenetic analysis and multiple sequence alignment may be helpful to explain how the differences in the sequence of ScGolS1 causes its function to be different from those of ScGolS2 and ScGolS3.

\section{ScGolS1 up-regulated expression in response to freezing stress}

We used qRT-PCR to assay the expression of ScGolS1 in tissue cultured and potted seedlings of W3, the expression level of ScGolS1 gene in leaves was significantly higher than in roots and stems for both tissue cultured and potted seedlings, and the expression in the young leaves of potted seedlings was 
significantly higher than older leaves (Fig. 2a-b), indicating that plants in the seedling stage are more appropriate for subsequent freezing tolerance identification. GolS1 gene of wild potato species W3 was up-regulated expression with the decrease of temperature under different low temperature treatments, while they were not expressed or expressed in low level in B44, and there was no obvious expression pattern (Fig. 2c). Under the same continuous low temperature treatment $\left(-1^{\circ} \mathrm{C}\right)$, GolS1 gene was still not expressed or expressed in low levels in B44, but in W3, was up-regulated with the extension of freezing stress time (Fig. 2d), indicating that the GolS1 gene in W3 responded to freezing stress through upregulation of expression and resisted adversity.

\section{Overexpression of ScGolS1 improves the freezing tolerance in transgenic plants}

The expression vector CaMV35S-pBI121-ScGolS1 was introduced into potato cultivars 'Atlantic' (B44) and 'Desiree' (B7) using Agrobacterium-mediated gene transformation, and total 106 transgenic regenerated plants were obtained. The vector primer $73 \mathrm{~F} / 211 \mathrm{R}$ and a combination of vector primer and gene-specific primers was used to detect transgenic regenerated plants, and we estimated 20 transgenic plants for B44 (Fig. 3a-b). Low-temperature incubator temperature was $-2.0 \pm 0.5^{\circ} \mathrm{C}$; wild-type B44 leaves were frost damaged and chlorotic, and the plants were not able to recover from wilting. However, the leaves of transgenic lines B44-OE2 were still green and vigorous, and the plants grew well (Fig. 3c), indicating that overexpression of the $S c G o / S 1$ gene could improve freezing tolerance in the transgenic potato plants derived from the cultivars B44.

qRT-PCR analysis showed that the ScGolS1 expression level in the transgenic lines B44-OE2 during low temperature treatment was always higher than WT (B44), and was most significant at $12 \mathrm{~h}$. When the low temperature treatment time increased, the expression of ScGolS1 showed a pattern in which expression first increased and then decreased (Fig. 3d). Exposure to low temperatures can lead to increased cell membrane permeability and electrolyte leakage. We found that the relative conductivity of the overexpression lines B44-OE2 under low temperature stress was lower than that of the WT (B44), indicating that the overexpression of ScGolS1 reduced the degree of damage to the potato cell membrane (Fig. 3e). Malondialdehyde (MDA) is an important product of fatty acid peroxidation, and the MDA content can reflect the degree of cell membrane lipid peroxidation. Before freezing stress, the MDA content in the overexpression line B44-OE2 was lower than that in the WT (B44). Upon exposure to freezing stress, the MDA content in WT (B44) and the overexpression line B44-OE2 increased and then decreased, but the MDA content in the overexpression line B44-OE2 was always lower than in WT (B44) (Fig. 3f). After 12 hours of exposure to freezing temperatures, the reddish brown spots or patches on the leaves of WT (B44) plants following DAB staining were larger than those on the ScGo/S1-overexpression lines B44-OE2. The freezing damage to the leaves was obvious, indicating that the $\mathrm{H}_{2} \mathrm{O}_{2}$ content had increased significantly (Fig. $3 \mathrm{~g}$ ). In addition, we found the similar results in another transformed strain B7. Taking B7-OE4 as an example, the transcript level of GolS1 gene was the highest at $12 \mathrm{~h}$, and much higher than WT (B7) (Fig. S4a). Physiologically, the relative electrical conductivity of the line OE-4 plants was clearly lower than that of the WT under freezing stress (Fig. S4b). The MDA content was gradually increased with freezing stress treatment in the transgenic and WT plants, but the MDA content of the 
transgenic lines was lower than WT (Fig. S4c). DAB dye assays also showed that the color of WT (B7) was darker than that of the transgenic line B7-OE4, indicating that the leaves of WT (B7) were seriously damaged, leading to a large amount of peroxide leakage (Fig. S4d). These results suggested that ScGolS1 enchanced the antioxidant activity of potato cultivars B44 and B7 under freezing stress.

\section{Obtain the T-DNA insertion position of the transgenic lines}

In order to obtain the copy number effect of the introduced ScGolS1 geneof the introduced ScGolS1 gene and the effect of copy number on freezing tolerance in transgenic plants, we determined the number of TDNA insertions in the whole genome of the transgenic lines B44-OE1, B44-OE2, B44-OE6, B44-OE14 and B44-OE19, and found that there were two copies of the ScGolS1 gene in B44-OE2 and a single copy in the other four transgenic lines. Specifically, the T-DNA insert in B44-OE1 and B44-OE6 was found to be located in two different positions on chr03 (Fig. 4c-d), the T-DNA insert in B44-OE14 and B44-OE19 were located on chr10 and chr01, respectively (Fig. 4e-f), while in B44-OE2 the two inserts were located on chr06 and chr07, respectively (Fig. 4a-b). The preliminary phenotype identification results showed that the freezing-tolerance of B44-OE2 with 2 copies is stronger than that of B44-OE1 with only 1 copy (Fig. S5). This indicated that the increase in potato freezing tolerance might be related to the inserted copy number of the ScGols 1 gene, that is, the gene dosage plays an important role on freezing tolerance level in ScGols1 transgenic lines, but the results have yet to be further verified.

\section{Overexpression of ScGolS1 altered CBF pathway and ERFs transcript level}

Experiments on ScGolS1 overexpression affecting the CBF pathway was carried out. The $C B F$ gene family in potato includes four members. The expression levels of $C B F 1, C B F 2$, and $C B F 3$ in the B44-OE2 line increased rapidly after $12 \mathrm{~h}$ of freezing stress treatment and peaked at $24 \mathrm{~h}$, and were significantly higher than WT, but interestingly CBF4 was not induced by freezing signal (Fig. 5a-d) .Moreover, CBF downstream cold responsive genes COR47 and COR413 were all induced by freezing treatment, while higher levels were observed in ScGolS1-overexpressing lines at $12 \mathrm{~h}$ compared with WT (B44) (Fig. 5e-f). The results indicated that $C B F$ transcription factor genes and their downstream $C O R$ genes were associated with $S c G o / S 1$ expression, $C B F 1, C B F 2$, and $C B F 3$ transcripts were induced in response to freezing stress. So CBFs might be rapidly activated at low temperature, which in turn induced the expression of a group of downstream cold-responsive genes such as COR47 and COR413 and enhances the freezing tolerance in potato plants.

In addition, low temperature stress can also promote the biosynthesis of ethylene (ET). Our qRT-PCR results showed that transcription level of the ERF3, ERF4 and ERF6 genes in the overexpression line B44OE2 was higher than WT (B44) at $12 \mathrm{~h}$ and $24 \mathrm{~h}$ of freezing treatment (Fig. $5 \mathrm{~g}-\mathrm{i})$. The increase in ERF gene expression could promote the biosynthesis of $\mathrm{ET}$, thereby regulating downstream defense responses to enhance freezing tolerance in potato.

Overexpression of ScGolS1 induced sugars accumulation in response to freezing treatment 
The sugar accumulation induced by low temperature plays a key role in protection of plants against freezing (Taji et al. 2002; Cunningham et al. 2003; Zhang et al. 2011; Zhuo et al. 2013). Quantitative realtime PCR was used to analyze the expression of genes in the RFOs metabolic pathway, and the results showed that overexpression of SCGolS1 under freezing condition increased the expression of MIPS, RS, and STS, especially after $12 \mathrm{~h}(R S)$ and $48 \mathrm{~h}$ (STS) (Fig. 6a-c). This showed that overexpression of the $S c G o / S 1$ could regulate the metabolic balance of inositol, galactinol, inositol, raffinose, and stachyose in the metabolism of RFOs, and thus improved freezing tolerance in potato. Compared to WT (B44), the content levels of fructose, glucose, raffinose, sucrose, and inositol were all higher in ScGolS1 overexpression plants (Fig. 6d-h). Moreover, raffinose, sucrose and inositol down-regulated expression after freezing treatment, and galactinol was not detected. These results indicated that ScGolS1 expression regulated MIPS, STS, and RF expression level and in turn altered RFOs accumulation and maintained dynamic balance of soluble carbohydrate components in sugar metabolism.

\section{T-DNA insertion analysis indicates gene dosage plays an important role on potato freezing tolerance}

In order to obtain the copy number effect of the introduced ScGolS1 gene on freezing tolerance in transgenic plants, we determined the number of T-DNA insertions in the whole genome of the transgenic lines B44-OE1, B44-OE2, B44-OE6, B44-OE14 and B44-OE19, and found that there were two copies of the ScGolS1 gene in B44-OE2 and a single copy in the other four transgenic lines. Specifically, the T-DNA insert in B44-OE1 and B44-OE6 was found to be located in two different positions on chr03 (Fig. 3c-d), the T-DNA insert in B44-OE14 and B44-OE19 were located on chr10 and chr01, respectively (Fig. 3e-f), while in B44-OE2 the two inserts were located on chr06 and chr07, respectively (Fig. 3a-b). The preliminary phenotype identification results showed that the freezing-tolerance of B44-OE2 with 2 copies is stronger than that of B44-OE1 with only 1 copy (Fig. S5). This indicated that the increase in potato freezing tolerance might be related to the inserted copy number of the $S c G o l s 1$ gene, that is, the gene dosage plays an important role on freezing tolerance level in ScGols 1 transgenic lines, but the results have yet to be further verified.

\section{Discussion}

Among the wild potato species, $S$. commersonii and $S$. acaule are considered to be the coldest tolerant, and they are also regarded as important genetic resources for improving freezing tolerance in commercial potato cultivars. S. commersonii is a stemless wild potato species. The appraisal of cold-tolerance experiments showed that $\mathrm{W} 3$ could still recover its morphology at $-5^{\circ} \mathrm{C}$, and field experiment also proved that its freezing tolerance was stronger than other wild potato materials in our study. Therefore, $S$. commersonii is an ideal freezing tolerance diploid wild species resource for studying potato freezing tolerance.

RFOs plays an important role in osmotic adjustment in plants, which enables them to resist biological and abiotic stresses. The rate-limiting enzyme GolS in the RFOs biosynthetic pathway has also attracted considerable attention. In recent years, GolS genes have been cloned from various plant species, and it 
has been shown that GolS proteins play an important role in stress resistance of plants (Gu et al. 2013). There are differences in the number of genes encoding GolS family members in different plants. In this study, the three homologous genes ScGolS1, ScGolS2, and ScGolS3 in the wild diploid potato species $S$. commersonii were cloned and analyzed, and the function of ScGolS1 was determined in transgenic plants of S. tuberosum. We found that ScGolS1 and ScGolS3 has two introns, while ScGolS2 has three, implying that there might be differences in the functions of these three genes. Further homology analysis revealed the presence of the relatively conserved manganese ion $\left(\mathrm{Mn}^{2+}\right)$ binding domain $\mathrm{DGD}$ that is necessary for the GolS protein to perform its catalytic function. In addition, there are significant differences between the $\mathrm{N}$ - and the $\mathrm{C}$-terminal sequences of GolS proteins from four wild Solanum species and tobacco (Fig. 1a), indicating that the different GolS proteins may differ in their substrate binding capabilities and catalytic activities. In the phylogenetic analysis, GolS proteins from five different Solanaceae species were found to be closely related and they clustered in three clades (Fig. 1b). Under low temperature stress, tomato $S / G o / S 2$ was found to be up-regulated, but $S / G o / S 1$ was either not expressed or was expressed at a very low level (Liu et al. 2019). We speculate that ScGolS3, which is in clade I with SIGolS2, has a stronger ability to induce raffinose accumulation than ScGolS1 and ScGolS2. The transcriptional responses of the different GolSgenes in plants in response to various stresses are quite complex. The GolS genes in the same clade can respond to different stresses, and different GolS genes can also be induced by the same stress, which is worthy of further study.

The expression characteristics of genes in different tissues are indicative of gene functions. qRT-PCR analysis showed that ScGolS1 was expressed at the highest level in S. commersonii leaves, and that expression in young leaves was higher than in old leaves. This indicates that ScGolS1 overexpression improves freezing tolerance in potato, and that plants should be assayed for freezing tolerance when they are young. In addition, the relative expression levels of ScGolS2 and ScGolS3 in S. commersonii was young leaves>old leaves>stems>roots (Fig. S2a-b, 2e-f). In tomato, the expression levels of S/GolS1 and SIGolS4 in both old and young leaves were low. The expression of SIGo/S2 in old leaves was higher than in young leaves, while the expression of SIGolS3 in young leaves was higher than in old leaves. It was speculated that $S / G o / S 2$ is related to sugar transport and storage in senescent leaves, but only SIGolS2 and SIGolS4 show a transcriptional response to low temperature stress (Liu et al. 2019). The expression of VhGolS1 and VhGolS2 during seed development in hairy vetch (Vicia hirsuta) resulted in the accumulation of raffinose in the seed, which gave the seed the ability to resist dehydration (Gojło et al. 2015). Among the nine GolS genes in Populus tomentosa, PtrGolS4 and PtrGolS6 were found in root tips, stems, young leaves and both were expressed in mature leaves, while PtrGolS3 and PtrGolS7 were expressed in roots and stems, and the nine genes were also functionally different (Zhou et al. 2014). Three GolS genes in Salvia miltiorrhiza also showed different tissue expression characteristics (Wang et al. 2012). In our research, the expression characteristics of ScGolS1 in different tissues implied that its function might be different.

Agrobacterium tumefaciens-mediated transformation is the most widely used system to transfer foreign genes into the genomes of plants (Nadolska et al. 2007). There are three ways to integrate exogenous 
genes in the host genome: (1) single copy unit site integration: this integration method is the simplest and easiest to analyze, but not all single copy insertions at individual sites are complete single copy insertions. In most cases, the boundary sequence has been modified (Pawlowski et al. 1998). (2) Tandem concatemer integration of more than one copy at the same site, the transforming plasmid is integrated into the host genome in the form of only one or a few complete multiple copies in tandem, and incomplete plasmids are often attached to one or both ends (Kumar et al. 2000). (3) A single copy or multiple copies of the transgene are integrated at multiple sites, often on more than one chromosome. This integration pattern is more complicated and difficult to analyze, and has been found in transgenic plants obtained by both Agrobacterium-mediated and particle gun transformation (Yang et al. 1998; Vaira et al. 2000). In this study, high-efficient thermal asymmetric interlaced PCR (hiTAIL-PCR) was used to clone and analyze the double-flanking sequences of the T-DNA insertion sites in the ScGolS1 transgenic lines (Fig. 4). Most of the transgenic lines were found to have one copy of the ScGolS1 T-DNA construct, but the integration positions were different. The B44-OE2 line located on potato chromosomes chr06 and chr07, while the remaining transgenic lines have only a single copy. Our analysis showed that the freezing tolerance of B44-OE2 was stronger than that of B44-OE1, which might be related to the number of copies and the relative expression level of ScGolS1 in the transgenic lines.

Under low temperature stress, plant growth is reduced, leaves are wilted, flowers and fruits fall off, and death can occur, which seriously affects crop yield and quality. At the physiological and metabolic levels, the damaged caused by low temperatures is mainly reflected in changes to the activities of certain enzymes and the reduced photosynthesis rate (Thordal et al. 1997; Ruelland et al. 2010), as well as in the damage to the structure and stability of cell membranes (Seo et al. 2010; Matteucci et al. 2011). In this study, the full-length CDS of ScGolS1 was cloned from the diploid freezing-tolerant wild species $S$. commersonii (Fig. S3a), and the function of the ScGolS1 gene was studied through Agrobacteriummediated genetic transformation of $S$. tuberosum cultivars. PCR amplification was used to identify the transgenic lines of B44 and B7 that carry the ScGolS1 gene. Under freezing stress, the leaves of the transgenic lines were less damaged and the plants had a higher survival rate (Fig. 3c). qRT-PCR analysis showed that the GolS1 expression level in the overexpression strains was higher than WT (Fig. 3d; Fig. S4a). Measurements of physiological and biochemical indicators showed that the transgenic lines had significantly reduced leaf electrolyte permeability and MDA content in response to freezing stress (Fig. 3ef; Fig. S4b-c). In conclusion, the determination of various physiological indicators showed that overexpression of ScGolS1 gene could significantly improve freezing tolerance of potato cultivars B44 and B7.

$C B F$ cold response pathway plays an important role in freezing tolerance of plants, and it regulates 10 to $20 \%$ of COR genes during cold acclimation (Park et al. 2015; Jia et al. 2016; Zhao et al. 2016). CBF pathway is downstream of cold triggered $\mathrm{Ca}^{2+}$ signal (Ding et al. 2019). CBF1, CBF2, and CBF3 play key roles in the freezing stress-response signaling pathway in Arabidopsis thaliana as transcriptional activators, and could improve freezing tolerance in plants by combining with CRT/DRE elements to regulate the expression of downstream genes such as RD29A, COR15a, and COR15b (Chinnusamy et al. 
2007). In our study, qRT-PCR analysis showed that overexpression of ScGolS1 promoted the expression of the $C B F$ gene family, showing that $S c G o l S 1$ might improve freezing tolerance in potatoes by relying on the CBF pathway.

Ethylene participates in the regulation of plant growth and development and in the response to biotic and abiotic stresses. Ethylene responsive transcription factors ( $E R F s)$ play an important role in the plant response to unfavorable environmental conditions and pathogens. A previous study showed that galactosyl inositol acts as a sugar molecule signal in tomato to induce the up-regulation of ERF gene expression in the ethylene signaling pathway to increase freezing tolerance in tomato (Liu et al. 2019). Overexpression of both grape VaERF057 and VaERF080 genes in Arabidopsis significantly improved the freezing tolerance of transgenic Arabidopsis lines (Sun et al. 2016). Overexpression of the wheat TaPIE1 gene activated the expression of defense and stress-related genes in the ethylene signaling pathway, and improved the tolerance of transgenic wheat to low temperature stress (Zhu et al. 2014). In this study, the transcription levels of ERF3, ERF4, and ERF6 in the ScGo/S1-overexpression line B44-OE2 were higher than that in WT (B44) at 12 and $24 \mathrm{~h}$ of low temperature stress, and the expression of ERFgenes was upregulated. Besides, the expression levels of other genes in the RFOs metabolic pathways such as MIPS, $R S$, and STS also increased accordingly; this may be one of the reasons for maintaining the balance of sugar metabolism, and the ethylene signaling pathway was involved in this regulation process. Therefore, overexpression of ScGolS1 induces the balance of RFOs and other soluble sugars, which further act as sugar signaling molecules to promote the up-regulated expression of ERF transcription factors, feedback the regulation of the ET signaling pathway, and enhance the activity of $C B F$ transcriptional activators ( $C B F 1, C B F 2$, and $C B F 3$ ), and then promotes expression of the downstream freezing-responsive genes COR47 and COR413, improving freezing tolerance in the potato cultivar B44. These findings provide useful information for potato freezing-resistant breeding..

\section{Conclusion}

Overexpression of the ScGolS1 gene from S. commersonii in S. tuberosum cultivars can significantly improve freezing tolerance in transgenic potato plants. Physiological and biochemical analyses show that the relative conductivity and MDA content of the transgenic potato plants decreased compared with WT. Our results demonstrate that ScGolS1 induces RFOs metabolic pathway related genes expression under freezing stress, and affects the balance of soluble carbohydrate components in sugar metabolism, which feedback regulates the expression of ERF transcription factors and the CBF pathway of the transgenic potato plants and thereby improves freezing tolerance of potato. These results provide a theoretical basis and genetic resources for potato freezing-resistant breeding.

\section{Declarations}

Acknowledgments 
This work was supported by National Natural Science Foundation of China (31561143006), China Agriculture Research System (CARS-9), and the Chinese Academy of Agricultural Sciences Innovation Project (CAAS-ASTIP-IVFCAAS)

\section{Author contribution statements}

Feiyan He designed the study, performed the experiments, wrote the original draft. Jianfei Xu and Yinqiao Jian performed the data analysis. Shaoguang Duan and Jun Hu performed phenotype test. Liping Jin designed the study. Guangcun Li designed the study, reviewed and edited the manuscript.

\section{Declaration of competing interest}

The authors declare that they have no known competing financial interests or personal relationships that could have appeared to influence the work reported in this paper.

\section{References}

1. Aversano R, Contaldi F, Ercolano MR, Grosso V, lorizzo M, Tatino F, Carputo D (2015) The Solanum commersonii genome sequence provides insights into adaptation to stress conditions and genome evolution of wild potato relatives. Plant Cell 27:954-968. https://doi.org/10.1105/tpc.114.135954

2. Bachmann M, Keller MF (1994) Metabolism of the raffinose family oligosaccharides in leaves of Ajuga reptans L. Plant Physiol 105:1335-1345. https://doi.org/10.1104/pp.105.4.1335

3. Cao WH, Liu J, He XJ, Mu RL, Zhou HL, Chen SY, Zhang JS (2007) Modulation of ethylene responses affects plant salt-stress responses. Plant Physiol 143:707-719. https://doi.org/10.1104/pp.106.094292

4. Chen HH, Li PH (1980) Biochemical changes in tuber-bearing Solanum species in relation to frost hardiness during cold acclimation. Plant Physiol 66:414-421. https://doi.org/10.1104/pp.66.3.414

5. Chen YK, Palta JP, Bamberg JB (1999) Freezing tolerance and tuber production in selfed and backcross progenies derived from somatic hybrids between Solanum tuberosum $\mathrm{L}$. and $S$. commersonii Dun. Theor Appl Genet 99: 100-107. https://doi.org/10.1007/s001220051213

6. Chinnusamy V, Zhu J, Zhu JK (2007) Cold stress regulation of gene expression in plants. Trends Plant Sci 12:444-451. https://doi.org/10.1016/j.tplants.2007.07.002

7. Cunningham SM, Nadeau P, Castonguay Y, Laberge S, Volenec JJ (2003) Raffinose and stachyose accumulation, galactinol synthase expression, and winter injury of contrasting alfalfa germplasms. Crop Sci 43:562-570. https://doi.org/10.2135/cropsci2003.5620

8. Ding Y, Shi Y, Yang S (2019) Advances and challenges in uncovering cold tolerance regulatory mechanisms in plants. New Phytol 222:1690-1704. https://doi.org/10.1111/nph.15696

9. Eremina M, Rozhon W, Poppenberger B (2016) Hormonal control of cold stress responses in plants. Cell Mol Life Sci 73:797-810. https://doi.org/10.1007/s00018-015-2089-6 
10. Falavigna Vítor da Silveira, Denardi PD, Evelyn MY, Dos SHP, De OPRD, Márcia MP, Giancarlo P, Fernando RL (2018) Evolutionary diversification of galactinol synthases in Rosaceae: adaptive roles of galactinol and raffinose during apple bud dormancy. J Exp Bot 69:1247-1259. https://doi.org/10.1093/jxb/erx451

11. Gojło E, Pupel P, Lahuta LB, Podliński P, Kucewicz M, Górecki RJ (2015) The acquisition of desiccation tolerance in developing Vicia hirsuta seeds coincides with an increase in galactinol synthase expression and soluble a-d-galactosides accumulation. J Plant Physiol 184:37-48. https://doi.org/10.1016/j.jplph.2015.06.013

12. Gu L, Han Z, Zhang L, Downie B, Zhao T (2013) Functional analysis of the 5 ' regulatory region of the maize galactinol synthase 2 gene. Plant Sci 213:38-45. https://doi.org/10.1016/j.plantsci.2013.09.002

13. Guy CL, Huber JL, Huber SC (1992) Sucrose phosphate synthase andsucrose accumulation at low temperature. Plant Physiol 100:502-508. https://doi.org/10.1104/pp.100.1.502

14. Jambunathan $N$ (2010) Determination and detection of reactive oxygen species (ROS), lipid peroxidation and electrolyte leakage in plants. Plant Stress Tolerance. Methods in Molecular Biology. (Methods and Protocols) 639:291-297. https://doi.org/10.1007/978-1-60761-702-0_18

15. Jia Y, Ding Y, Shi Y, Zhang X, Gong Z, Yang S (2016) The cbfs triple mutants reveal the essential functions of $C B F s$ in cold acclimation and allow the definition of $C B F$ regulons in Arabidopsis. New Phytol 212: 345-353. https://doi.org/10.1111/nph.14088

16. Kumar S, Fladung M (2000) Transgene repeats in aspen: molecular characterisation suggests simultaneous integration of independent T-DNAs into receptive hotspots in the host genome. Mol Gen Genet 264:20-28. https://doi.org/10.1007/s004380000296

17. Liu Q, Kasuga M, Sakuma Y, Abe H, Miura S, Yamaguchi-Shinozaki K, Shinozaki K (1998) Two transcription factors, DREB1 and DREB2, with an EREBP/AP2 DNA binding domain separate two cellular signal transduction pathways in drought and low-temperature-responsive gene expression, respectively, in Arabidopsis. Plant Cell 10: 1391-1406. https://doi.org/10.1105/tpc.10.8.1391

18. Liu YD, Zhang L, Meng SD, Liu YF, Li TL (2019) Expression of galactinol synthase from Ammopiptanthus nanus in tomato improves tolerance to cold stress. J Exp Bot 71:435-449. https://doi.org/10.1093/jxb/erz450

19. Liu YG, Chen YL (2007) High-efficiency thermal asymmetric interlaced PCR for amplification of unknown flanking sequences. Biotechniques 43:649-656. https://doi.org/10.2144/000112601

20. Livak KJ, Schmittgen TD (2001) Analysis of relative gene expression data using real-time quantitative PCR and the 2(-Delta Delta C(T)) Method. Methods 25:402-408. https://doi.org/10.1006/meth.2001.1262

21. Matteucci M, D'angeli S, Errico S, Lamanna R, Perrotta G, Altamura MM (2011) Cold affects the transcription of fatty acid desaturases and oil quality in the fruit of Olea europaea L. genotypes with different cold hardiness. J Exp Bot 62:3403-3420. https://doi.org/10.1093/jxb/err013 
22. Nadolska-Orczyk A, Pietrusinska A, Binka-Wyrwa A, Kuc D, Orczyk W (2007) Diploid potato (Solanum tuberosum L.) as a model crop to study transgene expression. Cell Mol Biol Lett 12:206-219. https://doi.org/10.2478/s11658-006-0064-9

23. Nakano T, Suzuki K, Fujimura T, Shinshi H (2006) Genome-wide analysis of the ERF gene family in Arabidopsis and rice. Plant Physiol 140:411-432. https://doi.org/10.1104/pp.105.073783

24. Panikulangara TJ, Eggers-Schumacher G, Wunderlich M, Stransky H, Schöffl F (2004) Galactinol synthase1, a novel heat shock factor target gene responsible for heat-induced synthesis of raffinose family oligosaccharides in Arabidopsis. Plant Physiol 136:3148-3158.

https://doi.org/10.1104/pp.104.042606

25. Park S, Lee CM, Doherty CJ, Gilmour SJ, Kim Y, Thomashow MF (2015) Regulation of the Arabidopsis CBF regulon by a complex low-temperature regulatory network. Plant J 82:193-207. https://doi.org/10.1111/tpj.12796

26. Pawlowski WP, Somers DA (1998) Transgenic DNA integrated into the oat genome is frequently interspersed by host DNA. Proceedings of the National Academy of Sciences. 95: 12106-12110. https://doi.org/10.1073/pnas.95.21.12106

27. Prafull S, Uttam KN, Manoj M (2018) Stress-Inducible Galactinol Synthase of Chickpea (CaGolS) is implicated in heat and oxidative stress tolerance through reducing stress-induced excessive reactive oxygen species accumulation. Plant Cell Physiol 59:155-166. https://doi.org/10.1093/pcp/pcx170

28. Ruelland E, Zachowski A (2010) How plants sense temperature. Environ Exp Bot 69:225-232. https://doi.org/10.1016/j.envexpbot.2010.05.011

29. Salvi P, Kamble NU, Majee M (2018) Stress-inducible galactinol synthase of chickpea (CaGolS) is implicated in heat and oxidative stress tolerance through reducing stress-induced excessive reactive oxygen species accumulation. Plant Cell Physiol 59:155-166. https://doi.org/10.1093/pcp/pcx170

30. Sengupta S, Mukherjee S, Parween S, Majumder AL (2012) Galactinol synthase across evolutionary diverse taxa: Functional preference for higher plants? FEBS Letters 586:1488-1496. https://doi.org/10.1016/j.febslet.2012.04.003

31. Seo PJ, Kim MJ, Park JY, Kim SY, Jeon J, Lee YH, Park CM (2010) Cold activation of a plasma membrane-tethered $N A C$ transcription factor induces a pathogen resistance response in Arabidopsis. Plant J 61:661-671. https://doi.org/10.1111/j.1365-313X.2009.04091.x

32. Shimosaka E, Ozawa K (2015) Overexpression of cold-inducible wheat galactinol synthase confers tolerance to chilling stress in transgenic rice. Breed Sci 65:363-371.

https://doi.org/10.1270/jsbbs. 65.363

33. Sonali S, Sritama M, Papri B, Majumder AL (2015) Significance of galactinol and raffinose family oligosaccharide synthesis in plants. Front Plant Sci 6:656-669.

https://doi.org/10.3389/fpls.2015.00656

34. Strand A, Foyer CH, Gustafsson P, Gardestrom P, Hurry V (2003) Altering flux through the sucrose biosynthesis pathway in transgenic Arabidopsis thaliana modifies photosynthetic acclimation at low 
temperat-ures and the development of freezing tolerance. Plant Cell Environ 26:523-535. https://doi.org/10.1046/j.1365-3040.2003.00983.x

35. Sun X, Zhao T, Gan S, Ren X, Fang L, Karungo SK, Xin H (2016) Ethylene positively regulates cold tolerance in grapevine by modulating the expression of ETHYLENE RESPONSE FACTOR 057. Sci Rep 6:24066. https://doi.org/10.1038/srep24066

36. Sun Z, Qi X, Wang Z, Li P, Wu C, Zhang H, Zhao Y (2013) Overexpression of TsGOLS2, a galactinol synthase, in Arabidopsis thaliana enhances tolerance to high salinity and osmotic stresses. Plant physiol Bioch 69: 82-89. https://doi.org/10.1016/j.plaphy.2013.04.009

37. Taji T, Ohsumi C, luchi S, Seki M, Kasuga M, Kobayashi M, Yamaguchi-Shinozaki K, Shinozaki K (2002) Important roles of drought and cold-inducible genes for galactinol synthase in stress tolerance in Arabidopsis thaliana. Plant J 29:417-426. https://doi.org/10.1046/j.09607412.2001.01227.x

38. Theocharis A, Clément C, Barka EA (2012) Physiological and molecular changes in plants grown at low temperatures. Planta 235:1091-1105. https://doi.org/10.1007/s00425-012-1641-y

39. Thordal-Christensen $\mathrm{H}$, Zhang Z, Wei Y, Collinge DB (1997) Subcellular localization of $\mathrm{H}_{2} \mathrm{O}_{2}$ in plants. $\mathrm{H}_{2} \mathrm{O}_{2}$ accumulation in papillae and hypersensitive response during the barley-powdery mildew interaction. Plant J 11:1187-1194. https://doi.org/10.1046/j.1365-313X.1997.11061187.x

40. Vaira AM, Berio T, Accotto GP, Vecchiati M, Allavena A (2000) Evaluation of resistance in Osteospermum ecklonis (DC.) Norl. plants transgenic for the $\mathrm{N}$ protein gene of tomato spotted wilt virus. Plant Cell Rep 19:983-988. https://doi.org/10.1007/s002990000226

41. Vega SE, Bamberg JB (1995) Screening the US potato collection for frost hardiness. Am Potato J 72:13-21. https://doi.org/10.1007/BF02874375

42. Wang D, Yao W, Song Y, Liu W, Wang Z (2012) Molecular characterization and expression of three galactinol synthase genes that confer stress tolerance in Salvia miltiorrhiza. J Plant Physiol 169:1838-1848. https://doi.org/10.1016/j.jplph.2012.07.015

43. Wang Y, Liang C, Meng Z, Li Y, Abid MA, Askari M, Guo S (2019) Leveraging Atriplex hortensis choline monooxygenase to improve chilling tolerance in cotton. Environ Exp Bot 162:364-373. https://doi.org/10.1016/j.envexpbot.2019.03.012

44. Yang H, Singsit C, Wang A, Gonsalves D, Ozias-Akins P (1998) Transgenic peanut plants containing a nucleocapsid protein gene of tomato spotted wilt virus show divergent levels of gene expression. Plant Cell Rep 17:693-699. https://doi.org/10.1007/s002990050467

45. Yi SY, Kim JH, Joung YH, Lee S, Kim WT, Yu SH, Choi D (2004) The pepper transcription factor CaPF1 confers pathogen and freezing tolerance in Arabidopsis. Plant Physiol 136:2862-2874. https://doi.org/10.1104/pp.104.042903

46. Yin Y, Chen H, Hahn MG, Mohnen D, Xu Y (2010) Evolution and function of the plant cell wall synthesis-related glycosyltransferase family 8. Plant Physiol 153:1729-1746. https://doi.org/10.1104/pp.110.154229 
47. Zhang LL, Zhao MG, Tian QY, Zhang WH (2011) Comparative studies on tolerance of Medicago truncatula and Medicago falcata to freezing. Planta 234:445-457. https://doi.org/10.1007/s00425011-1416-x

48. Zhang Z, Huang R (2010) Enhanced tolerance to freezing in tobacco and tomato overexpressing transcription factor TERF2/LeERF2 is modulated by ethylene biosynthesis. Plant Mol Biol 73:241249. https://doi.org/10.1007/s11103-010-9609-4

49. Zhao C, Zhang Z, Xie S, SiT, Li Y, Zhu JK (2016) Mutational evidence for the critical role of CBF transcription factors in cold acclimation in Arabidopsis. Plant Physiol 171:2744-2759. https://doi.org/10.1104/pp.16.00533

50. Zhou J, Yang Y, JYu J, Wang L, Yu X, Ohtani M, Zhuge Q (2014) Responses of Populus trichocarpa galactinol synthase genes to abiotic stresses. J Plant Res 127:347-358. https://doi.org/10.1007/s10265-013-0597-8

51. Zhou Y, Liu Y, Wang S, Shi C, Zhang R, Rao J, Wei C (2017) Molecular cloning and characterization of galactinol synthases in with different responses to biotic and abiotic stressors. J Agr Food Chem 65:2751-2759. https://doi.org/10.1021/acs.jafc.7b00377

52. Zhu JK (2016) Abiotic stress signaling and responses in plants. Cell 167:313-324. https://doi.org/10.1016/j.cell.2016.08.029

53. Zhuo C, Wang T, Lu S, Zhao Y, Li X, Guo Z (2013) A cold responsive galactinol synthase gene from Medicago falcata (MfGolSl) is induced by myo-inositol and confers multiple tolerances to abiotic stresses. Physiol Plant 149:67-78. https://doi.org/10.1111/ppl.12019

54. Zhu X, Qi L, Liu X, Cai S, Xu H, Huang R, Zhang Z (2014) The wheat ethylene response factor transcription factor pathogen-induced ERF1 mediates host responses to both the necrotrophic pathogen Rhizoctonia cerealis and freezing stresses. Plant Physiol 164:1499-1514. https://doi.org/10.1104/pp.113.229575

\section{Figures}


a

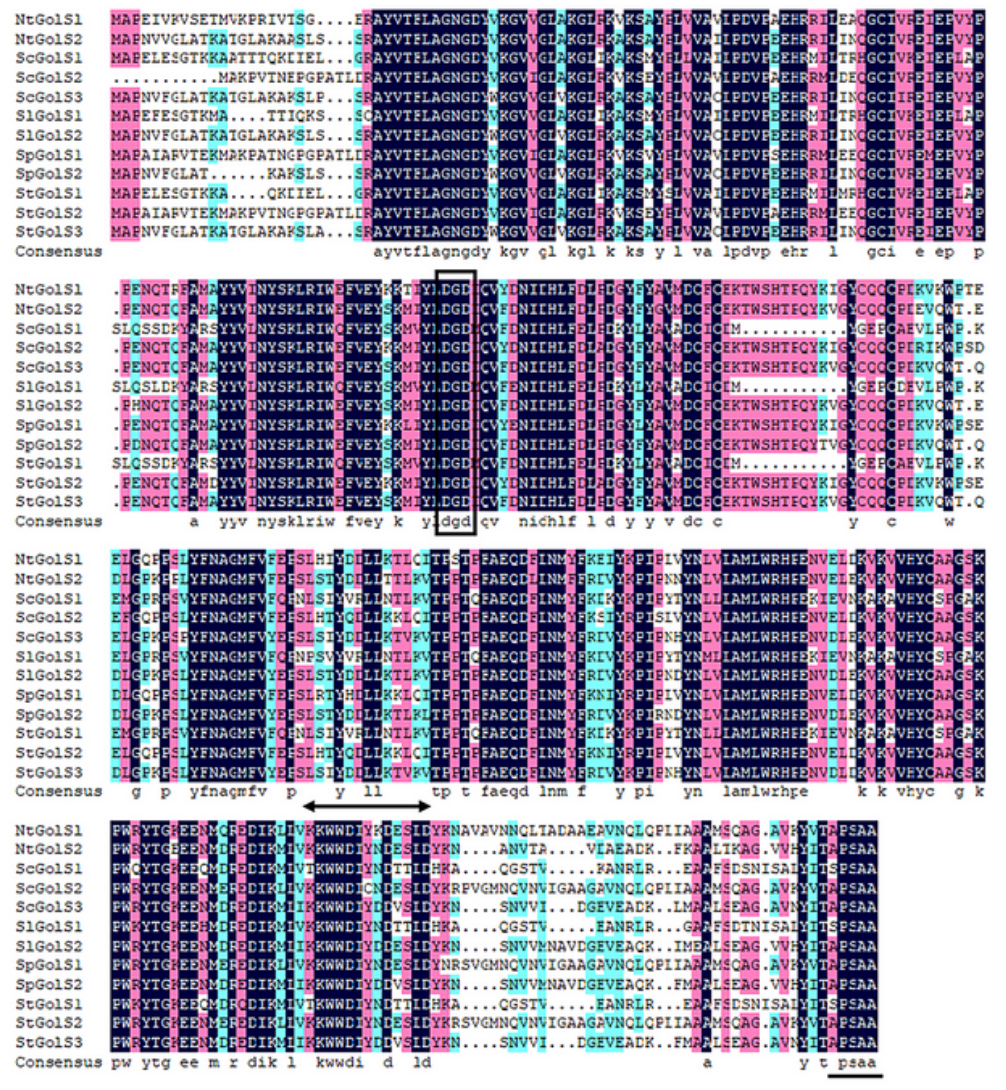

86
87
87
79
87
93
87
90
81
83
90
87
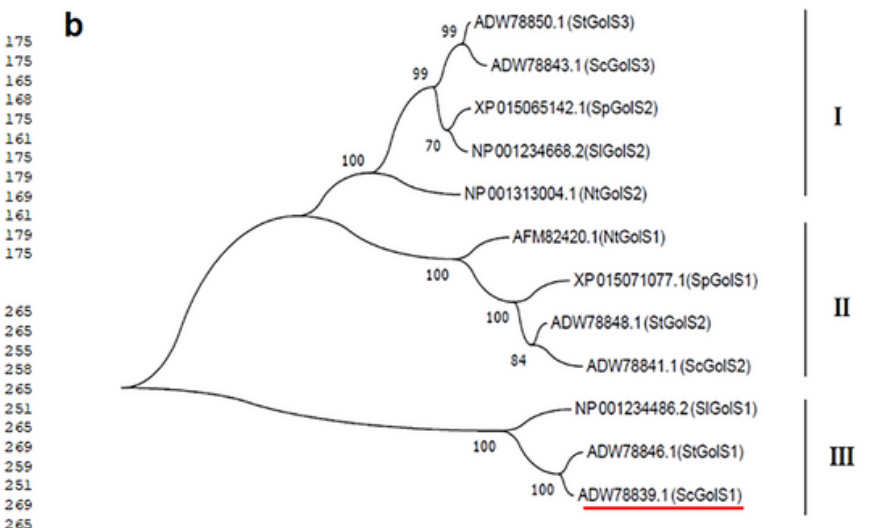

343
333
322
336
334
318
337
347
331
318
347
334

Figure 1

Sequence analysis of GolS. a Multiple sequence alignment of GolS proteins. b Phylogenetic relationship of GolS from five species in the Solanaceae. Black box, Black double-ended arrow and black horizontal line represent the manganese binding site DGD, the GolS substrate binding area, and C-terminal hydrophobic pentapeptide A(S)PSAA, respectively. ScGolS1 is underlined in red 

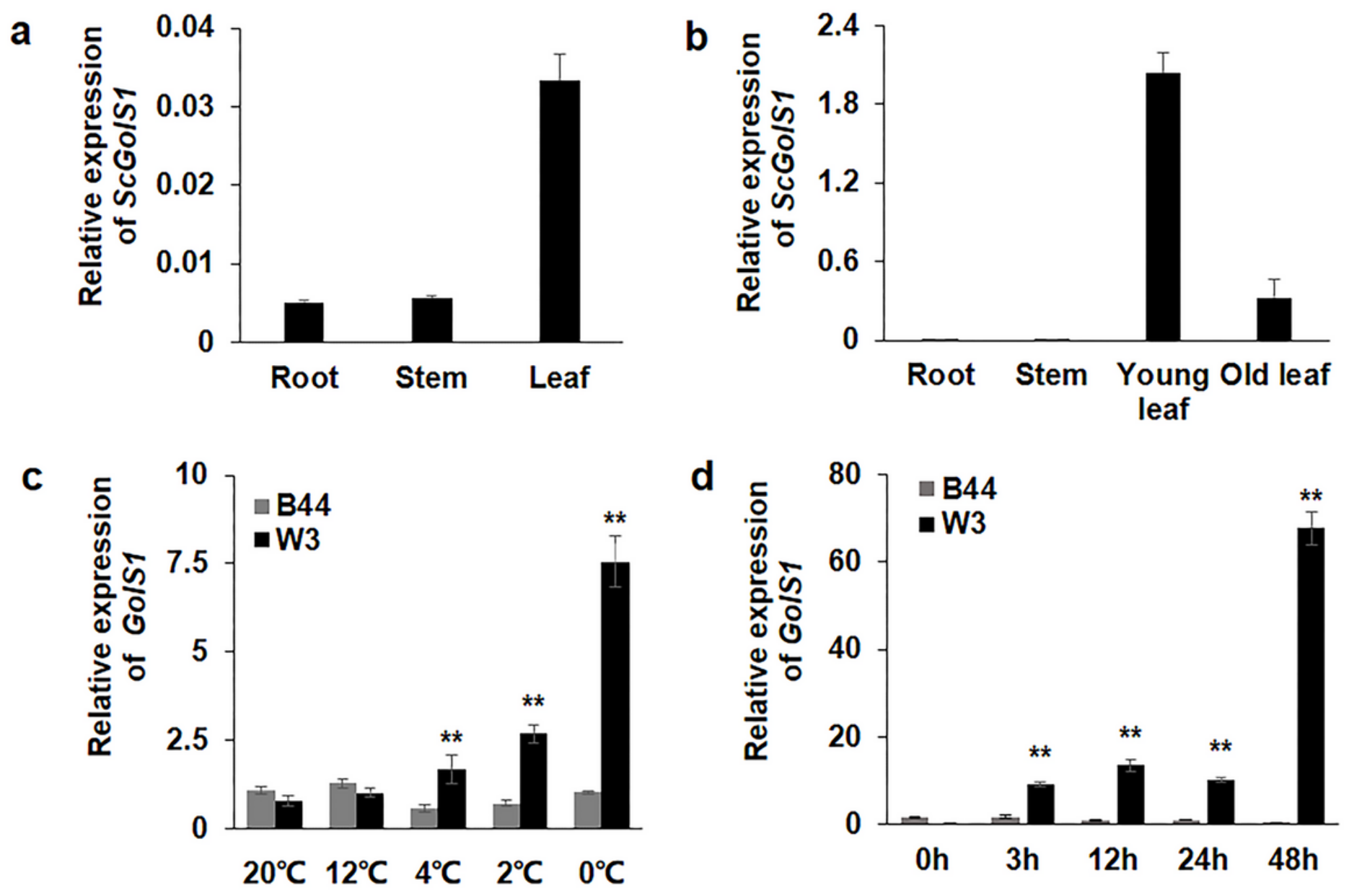

Figure 2

Expression analysis of GolS1 gene. a Expression analysis of ScGolS1 gene in roots, stems and leaves of W3 tissue cultured seedlings. b Expression analysis of ScGolS1 gene in roots, stems and leaves of W3 potted seedlings c Relative expression levels of GolS1 gene in B44 (S. tuberosum) and W3 (S.

commersonii) under low tempearture stress at $20^{\circ} \mathrm{C}, 12^{\circ} \mathrm{C}, 4^{\circ} \mathrm{C}, 2^{\circ} \mathrm{C}$ and $0^{\circ} \mathrm{C}$ for $24 \mathrm{~h}$. d Relative expression levels of GolS1 gene in B44 (S. tuberosum) and W3 (S. commersonii) under freezing stress at $-1^{\circ} \mathrm{C}$ for $0 \mathrm{~h}, 3 \mathrm{~h}, 12 \mathrm{~h}$, and $24 \mathrm{~h}$ 


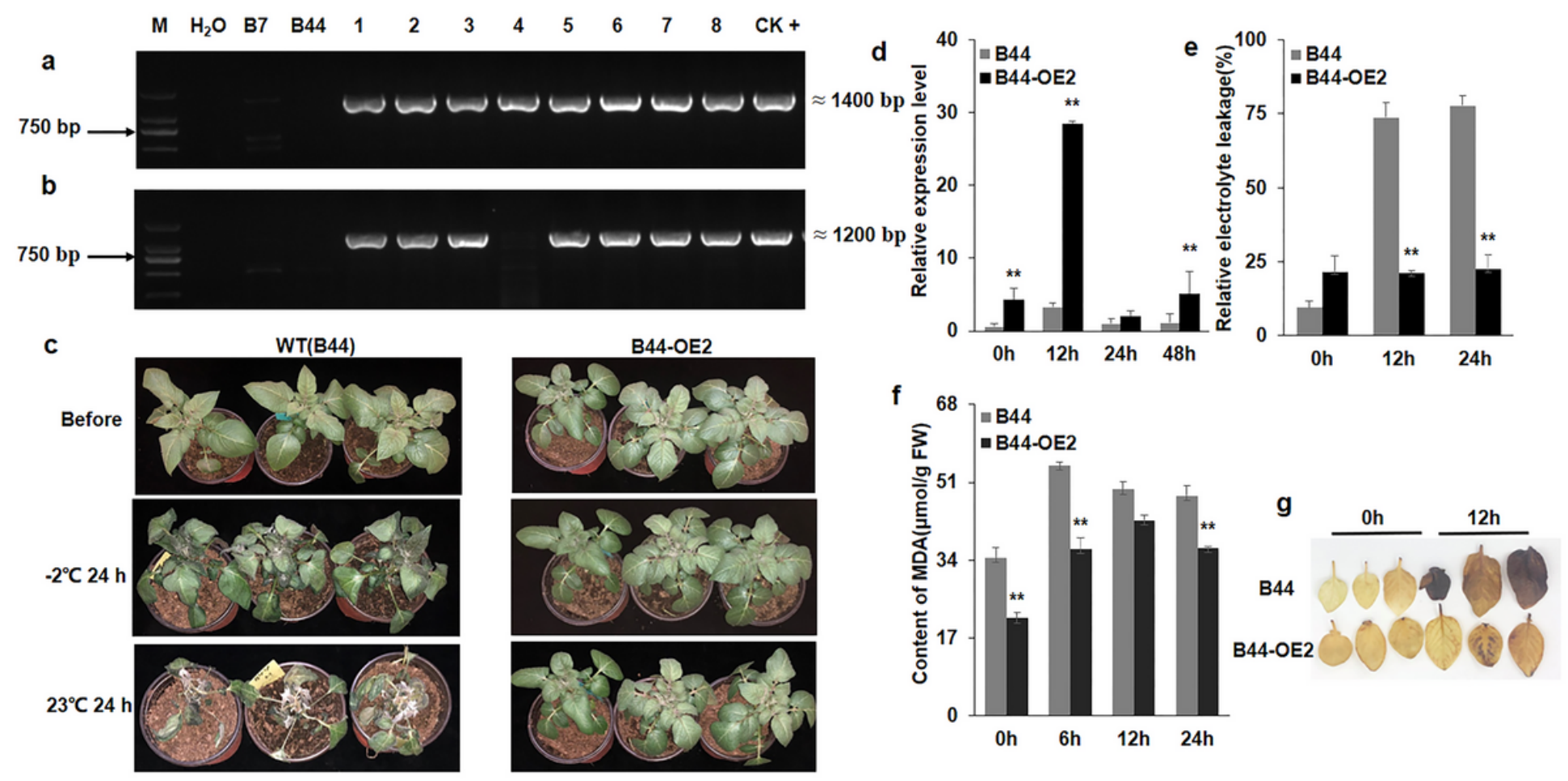

\section{Figure 3}

Identification of freezing tolerance of B44 transgenic lines. a PCR amplication identification with pBI121 vector primer 73F/211R. b PCR amplication identification with $\mathrm{pB} 1121$ vector forward primer $73 \mathrm{~F}$ and the ScGolS1 gene reverse primer. c Seedlings before freezing treatment, after $24 \mathrm{~h}$ at $-2^{\circ} \mathrm{C}$, and after recovery for $24 \mathrm{~h}$ at $23^{\circ} \mathrm{C}$. d Relative expression levels of ScGolS1 in WT (B44) and transgenic lines (B44-OE2) at 0 , 12,24 , and $48 \mathrm{~h}$ after exposure to $-1^{\circ} \mathrm{C}$ freezing stress. e Relative electrolyte leakage in WT (B44) and transgenic lines (B44-OE2) after freezing stress at $-1^{\circ} \mathrm{C}$ for 0,12 and $24 \mathrm{~h}$. $\mathrm{f}$ MDA contents after freezing stress at $-1^{\circ} \mathrm{C}$ for $0,6,12$, and $24 \mathrm{~h}$ in WT (B44) and transgenic lines (B44-OE2). g DAB staining of leaves exposed to $-1{ }^{\circ} \mathrm{C}$ freezing stress for $12 \mathrm{~h}$ in WT (B44) and transgenic lines (B44-OE2). Values represent means of three biological replicates with error bars indicating standard error of the mean. ** indicates a significant difference compared with the control at $p<0.01$ determined by Student's t-test 
a

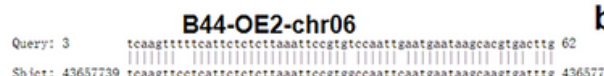

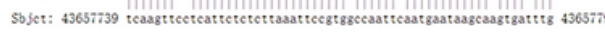
Query: 63 iactagtattacagtasagasastttaatctatagttagatasazastcasgtttactat: 122

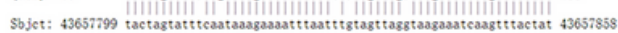

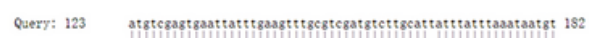

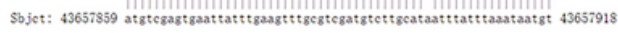

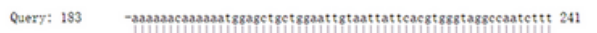

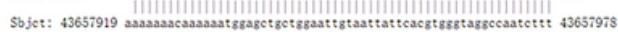

Query: 242 gatagcaacas---tacasatcaccaattzatcascactatettces 285

d Sbjet: 43657979 gatageascastactaceasatcaccasttzatcascactatcttcea 43655025

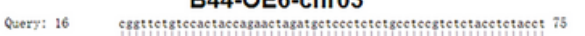

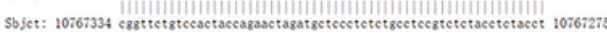

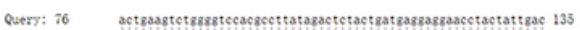

Sbjet: 10767274 actzasstetz8z8tccac8cettatasactetact gat zas8asgascetactatt gac 10767215

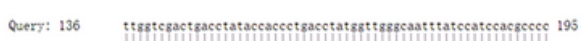

Sbjet: 10767214 ttastcgectzacetatacescectgacetat 88t t8886aatttatceatceac8ecee 10767155

Qtery: 196 ttetatceatasgastaacascetztrasaccetztctacacetcecgaastgtatctta 255

Sbjet: 10767154 tcetatccateagaatascascetgtzaasccetstctacacetcecgaatstatetta 10767095

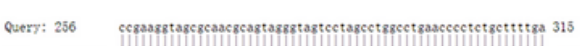

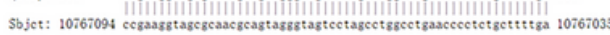

Query: 316 gagsetzatgetegz:zaace 335

Sbjet: 10767034 8agectgatgetegtzasce 10767015

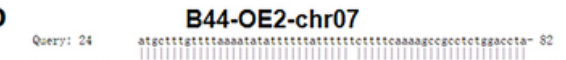

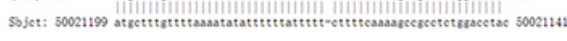

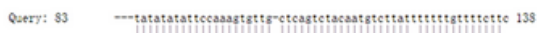

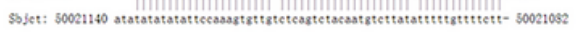

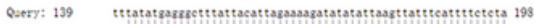

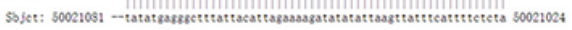

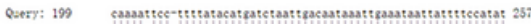

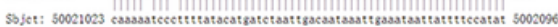

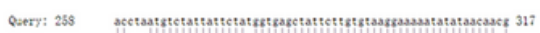

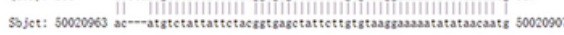

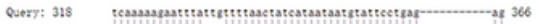

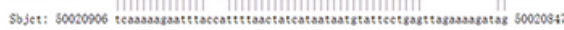

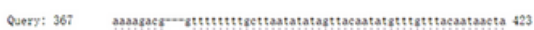

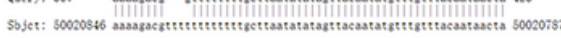

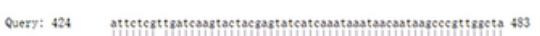

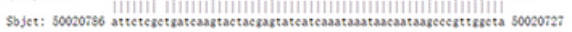

Query: 444 zasectzatzetazasace 503

\section{e}

\section{B44-OE14-chr10}

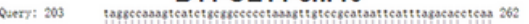

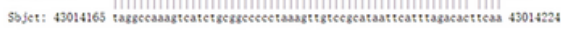

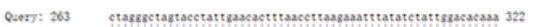

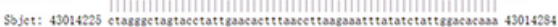

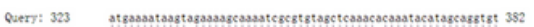

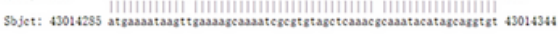

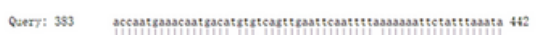

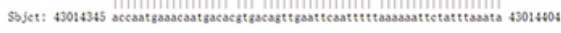

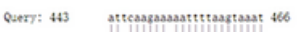
Sojet: 43014005 atccasasasaattttasttasat 4301422
C Query: 39 B44-OE1-chr03

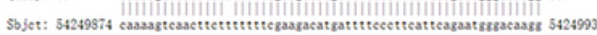

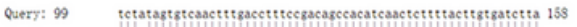

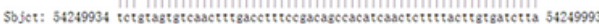

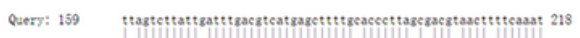
Sbjet: 54249994 tcagtettasttatttzacztcat 8azettttzascecttaacasczzasctettcaaat 54250053

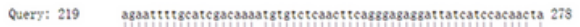

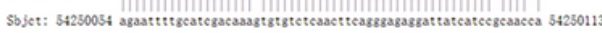

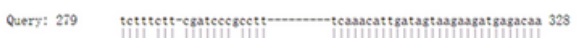

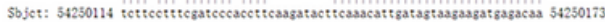

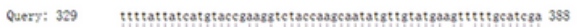
Sbjet: 54250174 ttttattatcatztacecastzectaccasscastatzttztatzacgtetttrcatega 54250233

f

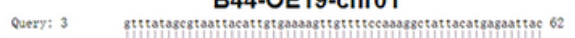

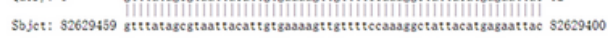

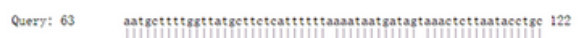

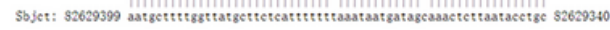

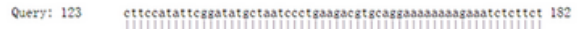

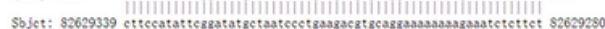

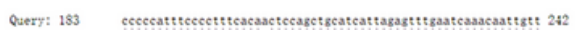
Sbjet: 82629279 cececattceecetttcacasetceasctgcatcattagagtttgaatcasacaattstt 82629220

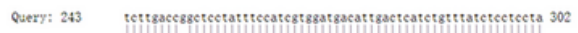

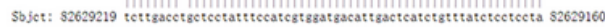

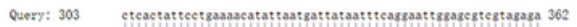

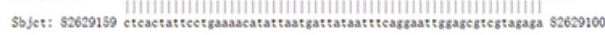

\section{Figure 4}

T-DNA insertion in transgenic plants. a-b Insertion position of B44 transgenic line OE2, chr06 and chr07. c Insertion position of B44 transgenic line OE1, chr03. $d$ Insertion position of B44 transgenic line OE6, chr03. e Insertion position of B44 transgenic line OE14, chr10. $f$ Insertion position of B44 transgenic line OE19, chr01 
a

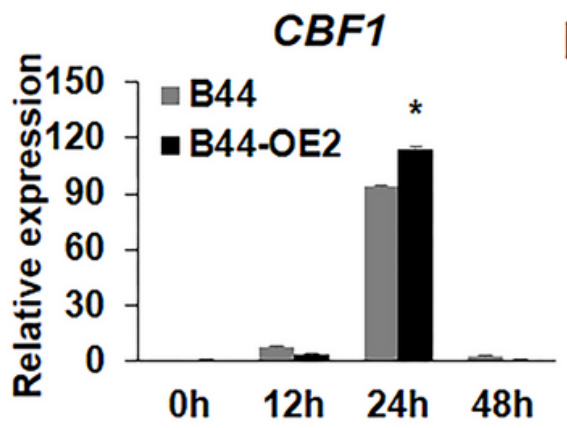

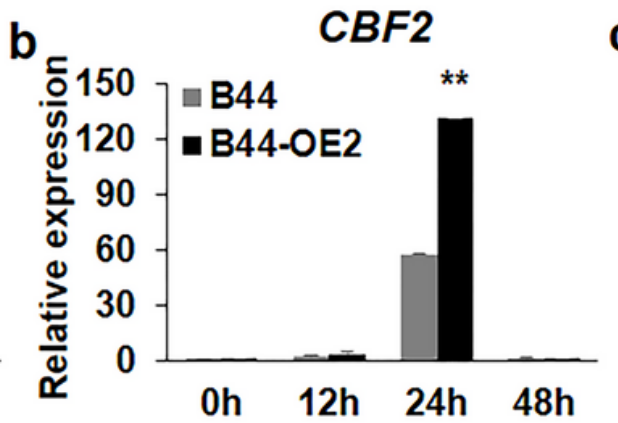

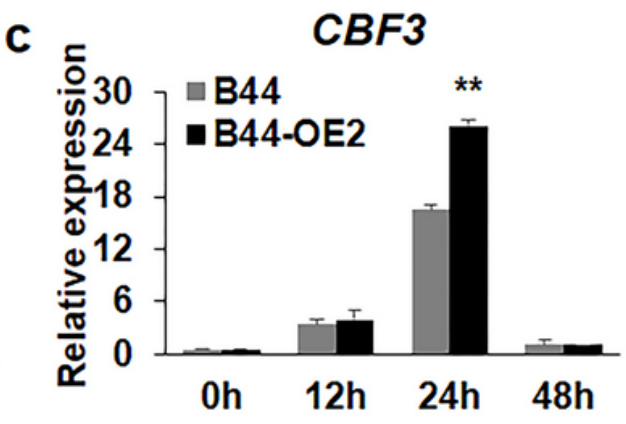

d

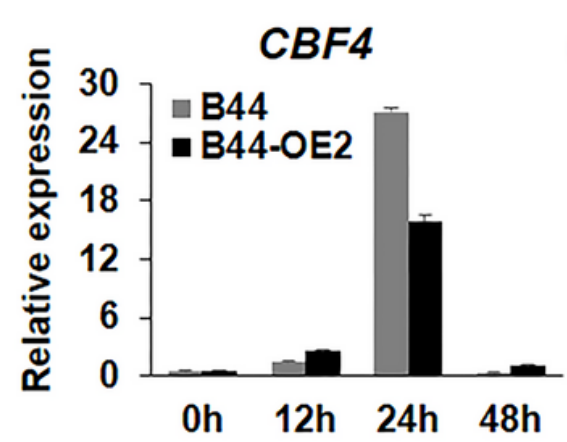

e

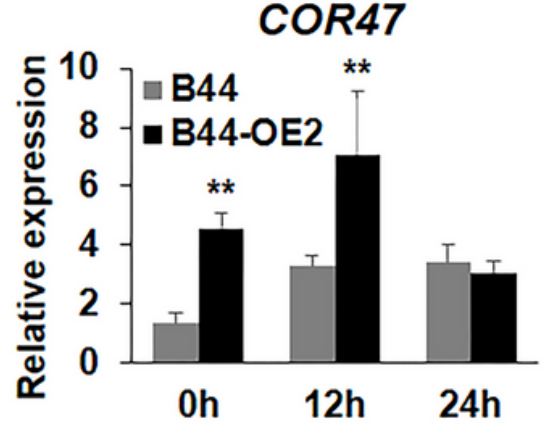

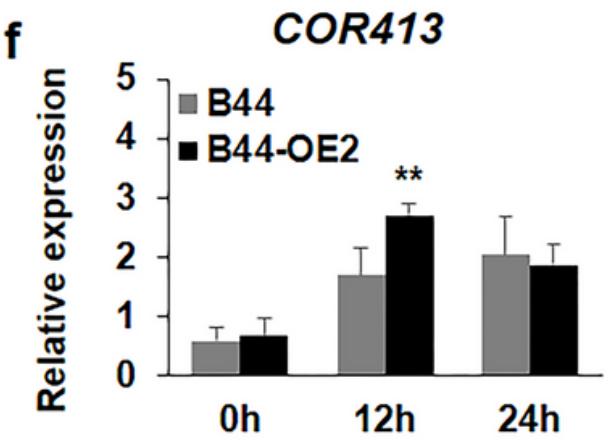
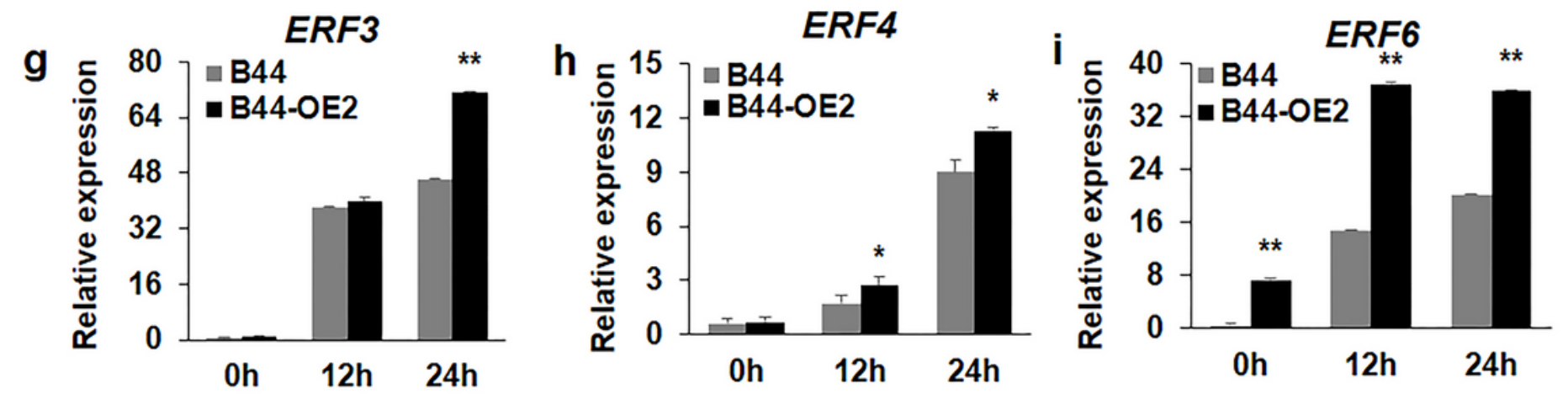

Figure 5

Analysis of transcripts of cold responsive genes in transgenic line B44-OE2 and WT (B44) exposed to freezing stress $\left(-1^{\circ} \mathrm{C}\right)$. EF-1 a was used to normalize theamount of template. Relative expression levels were calculated by $2-\Delta \Delta C$ Ct. Values are means $\pm S D(n=3)$. indicate a significant difference compared with WT (B44) at $\mathrm{P}<0.05$, by Student's t-test. ** indicates a significant difference compared with WT (B44) at $p<0.01$ determined by Student's t-test 

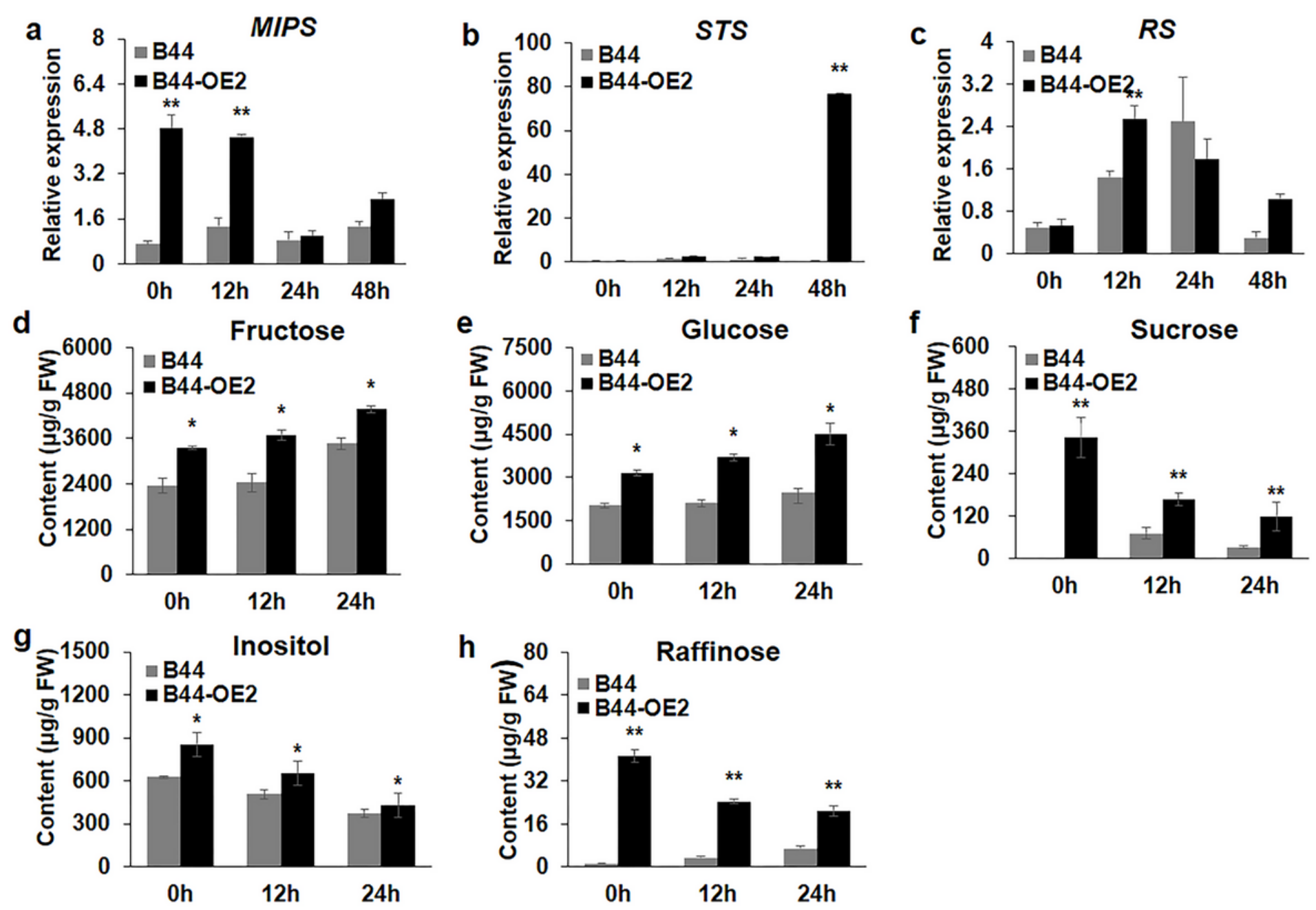

Figure 6

Analysis of trangscripts of RFOs metabolism related genes and sugars concentrations in transgenic potato plant B44-OE2 and WT. a-c Transcript levels of MIPS, STS and RS were determined after 0h, 12h, $24 \mathrm{~h}$ and $48 \mathrm{~h}$ of freezing treatment. $\mathrm{d}-\mathrm{h}$ Sugars concentrations were determined after $0 \mathrm{~h}, 12 \mathrm{~h}$ and $24 \mathrm{~h}$ of freezing treatment. Means of three replicates and standard errors are presented; Values are means \pm SD $(n=3)$. * indicate a significant difference compared with WT (B44) at $P<0.05$, by Student's t-test. ** indicates a significant difference compared with WT (B44) at $p<0.01$ determined by Student's t-test 


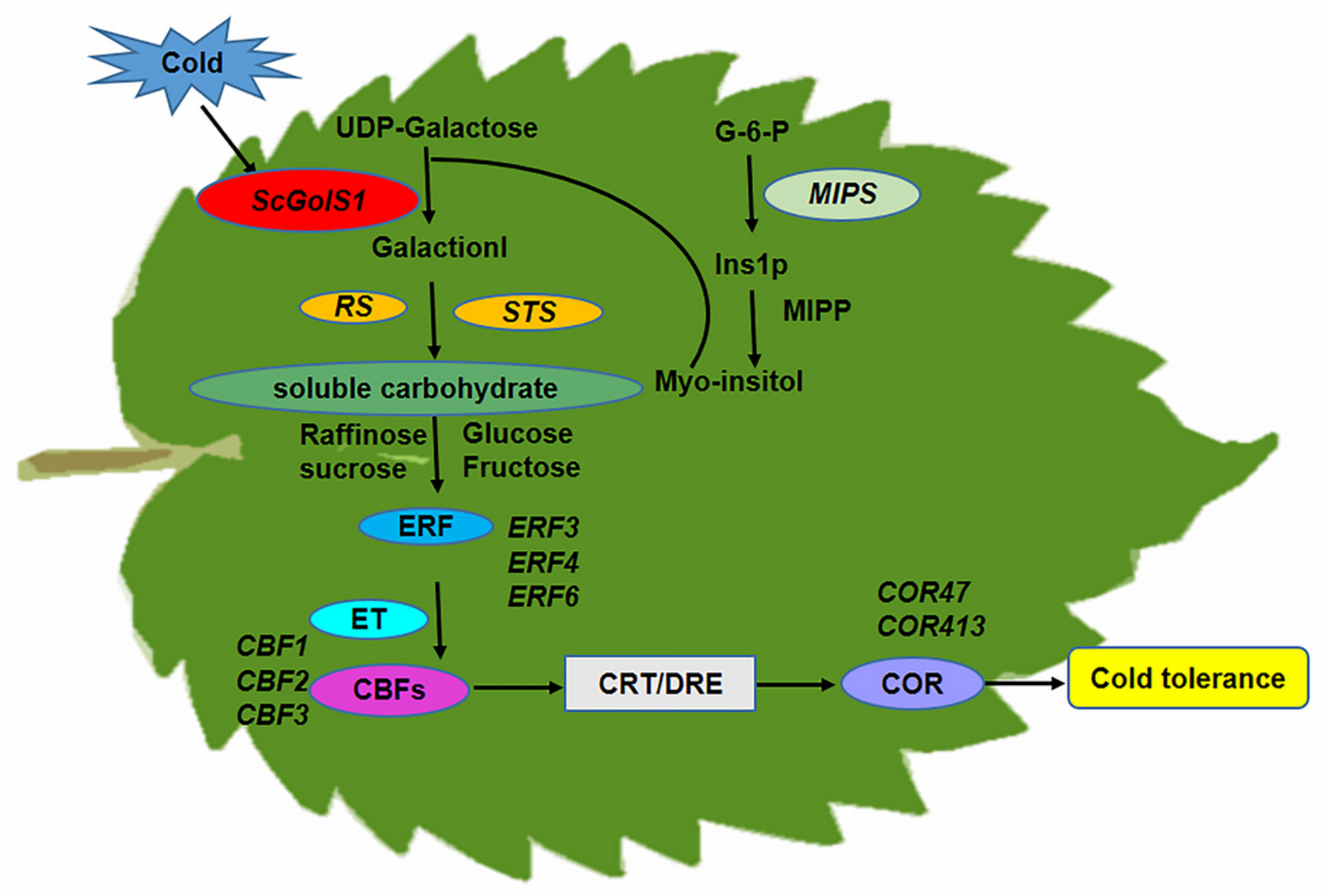

Figure 7

Diagram of a proposed model for regulation of ScGolS1 in freezing tolerance in transgenic potato

\section{Supplementary Files}

This is a list of supplementary files associated with this preprint. Click to download.

- supplementaryfile2DOCX16kb.docx

- supplymentaryfile1D0CX3.28MB.docx 